\title{
Um campo de experiências, afetações e "achismos"
}

\section{dilemas e desafios metodológicos em pesquisas empíricas sobre criminalidade, violências, (in) segurança e ativismos}

\author{
1 Universidade Federal Fluminense, Niterói-RJ-Brasil \\ (iD) https://orcid.org/oooo-0003-1007-6714 \\ Correo electrónico: anapaulamiranda@id.uff.br \\ 2 Universidade Federal Fluminense, Niterói-RJ-Brasil. \\ (iD) https://orcid.org/oooo-00o2-1481-414X \\ Correo electrónico: jacquelinemuniz@id.uff.br
}

\section{Resumo}

O artigo apresenta reflexões sobre pesquisas no campo da segurança pública, violências e ativismos no Brasil, a partir de experiências desenvolvidas pelas autoras, levando em consideração os dilemas de constituição desse campo temático. Salienta-se a importância das pesquisas empíricas, num recorte antropológico e os desafios de interlocução com o Direito. Discute ainda que a abordagem teórico-metodológica reflexiva sobre o Estado e as políticas públicas deve orientar também as análises sobre os ativismos, para evitar a homogeneização e generalização das classificações jurídico-políticas que dominam o campo. Com base nessa perspectiva apresenta-se um estudo de caso demonstrando a importância da multidimensionalidade e a situacionalidade em estudos sobre (in)segurança. Trata-se da metodologia desenvolvida para análise de percepções de risco, construída para identificar as situações sociais de violência que afetavam o trabalho regular de medição de energia elétrica, nos municípios de São Gonçalo e Duque de Caxias (Rio de Janeiro), para prevenção do furto.

\section{A field of experiences, biased impacts and assumptions: dilemmas and methodological challenges of empirical resear- ches on criminality, violences, (in)security and activisms}

\begin{abstract}
This paper presents reflections about researches on the field of public security, violences and activisms in Brazil, from experiences developed by the authors, considering the constitutive dilemmas of this thematic. It emphasizes the importance of empirical researches based on an anthropological construction
\end{abstract}

\section{Palauras-chave}

Pesquisas empíricas; Multidimensionalidade; Situacionalidade; Políticas públicas; segurança pública

\section{Key words}

Empirical researches; Multidimensionality; Situationality; Public policies; Public security 
and of the challenges of the interlocution with Law. Furthermore, the reflexive theoretic and methodological approach on State and public policies must also orient the analysis of activisms, to avoid homogenization and generalization of the juridical and political classifications which dominate the field. Based on this perspective, a case study is presented, demonstrating the importance of multidimensionality and situationality on studies about (in)security. It is a methodology developed for analysis on risk perceptions, constructed to identify social situations of violence which affected the regular work of measurement of electricity, on the cities of São Gonçalo and Duque de Caxias (Rio de Janeiro State), in order to prevent theft.

\section{Un campo de experiencias, afectaciones y suposiciones: Dile- mas y desafíos metodológicos en investigaciones empíricas sobre criminalidad, violencias, (in)seguridad y activismos}

\section{Resumen}

Palabras clave

Investigaciones empíricas; Multidimensionalidad; Situacionalidad; Políticas públicas; Seguridad pública
Este articulo presenta reflexiones sobre algunas investigaciones del campo de la seguridad pública, violencias y activismos en Brasil a partir de experiencias desarrolladas por las autoras considerando los dilemas constituyentes de este campo temático. Destaca la importancia de las investigaciones empíricas desde un recorte antropológico y los desafíos de interlocución con el derecho. Discute también que el enfoque teórico-metodológico reflexivo sobre el Estado y las políticas públicas deben orientar los análisis sobre activismos, para evitar la homogeneización y generalización de clasificaciones jurídico-políticas dominantes en el campo. Según esta perspectiva, se presenta un estudio de caso que demuestra la importancia de la multidimencionalidad y la situacionalidad en estudios sobre (in)seguridad. Se trata de la metodología desarrollada para el análisis de percepciones de riesgo, construida para identificar situaciones de violencia que afectaban el trabajo de medición de energía eléctrica -para prevenir su hurto- en dos ciudades del estado de Río de Janeiro.

\section{De onde partimos? Sobre o pensamento tutelar e suas ilusões de controle reflexivo}

A produção nas Ciências Sociais brasileiras sobre segurança pública e violências cresceu significativamente a partir de 1980 (Zaluar, 1999a, 1999b; Kant de Lima, Misse e Miranda, 2000; Adorno, 2001; Barreira e Adorno, 2010; Campos e Alvarez, 2017; Muniz, Caruso e Freitas, 2018). Com a redemocratização no Brasil, a chamada "questão da segurança", até então somente uma "questão de Estado", ingressou na agenda pública e mobilizou o interesse acadêmico. Assistiu-se a um processo político-científico de transformação de problemas sociais em sociológicos, com enfoque prioritário aos atores institucionais. Essa conversão trazia a expectativa de se produzir conhecimentos que possibilitassem a "reforma da segurança", ou melhor, a construção da "segurança cidadã". Buscava-se compor um acervo de saberes orientados para ação, que guiasse a intervenção estatal rumo a um horizonte que se acreditava promotor da 
cidadania para todos. Assim, as políticas públicas de segurança ampliaram o seu campo de atuação para além das agências da lei e seus integrantes através do reconhecimento e inclusão de novos atores na arena pública. Mostrava-se relevante "dar voz" aos representantes da sociedade civil organizada, dos movimentos sociais e das comunidades populares. Ressaltava-se o lugar de atores nos ativismos por luta de direitos como um recurso estratégico para a mudança do status quo e um tema de pesquisa. Salienta-se que o crescimento dessa produção científica comprometida com a "defesa e consolidação da democracia" revela um delineamento de linhas de pesquisa que espelharam, inicialmente, o universo dos dilemas e desafios a serem enfrentados. Revela também a inserção dos cientistas sociais nas políticas públicas e nos ativismos em direitos humanos. Muito do que se apresentava como problemática de pesquisa correspondia a respostas técnico-científicas para às necessidades governamentais, às demandas e às denúncias de distintos segmentos sociais.

O volume da produção científica enquadrada no guarda-chuva político-institucional da segurança pública não pode ser tratado propriamente como uma excepcionalidade. Afinal, os temas do controle social, conflito, coerção e desvio fazem parte do repertório clássico das Ciências Sociais desde a sua constituição. Também não é um traço exclusivo brasileiro que os estudos sobre segurança pública, em seu sentido amplo, um campo ainda emergente, tenha se estruturado em torno do fomento de pesquisas aplicadas voltadas para a produção de insumos para as políticas públicas. Cremos que a especificidade importante, no caso brasileiro, é a dificuldade de promoção de diálogos entre as Ciências Sociais, cujas abordagens privilegiam a pesquisa empírica ${ }^{1}$ (Antropologia/ Sociologia), e o Direito. Observa-se que os dilemas entre o "mundo da lei" concebido e as "leis do mundo" vividas pelos operadores da segurança e justiça criminal se apresentam no campo acadêmico como manobras de sentido, que expressam disputas e rupturas de monopólios temáticos. Ressalte-se que o senso comum político e acadêmico no campo da segurança é atravessado por uma visão prescritiva e instrumental das instituições e das práticas de controle social, e que ambiciona hegemonia de narrativa. As narrativas acadêmicas de cunho normativo-procedimental criam, como gostaria Bourdieu (2008), um efeito de intervenção ("basta fazer como prescrito") naquilo que é percebido socialmente como inadiável: o imediato do medo e da insegurança. Desfruta, portanto, de expressiva atenção política e de elevada visibilidade social uma vez que cria, no ato mesmo de sua enunciação como "dever ser", uma promessa de ordenação solucionadora, uma expectativa de controle e de normalização no "agora-já". Uma promessa dogmática que se faz interventora, e que as narrativas científicas empíricas, analítico-reflexivas não têm como se comprometerem: trazer o futuro prescrito no presente receitado. Ao considerarmos nossa tradição política tutelar, constata-se que o apetite político por uma ordem estática, vinda de cima, para impor uma harmonia uniforme aos que vêm de baixo, encontra terreno fértil em perspectivas jurídicas dogmáticas dissociadas do real vivido das práticas do direito.

Ressalte-se que, a partir dos anos 1970, a "segurança pública" apareceu como uma chave indexadora de concepções, proposições e práticas. Consiste em uma categoria de origem político-administrativa que circunscrevia a distribuição de poderes coercitivos entre instituições e o seu campo de execução exclusivo das Razões de Estado. Sua natureza política é, a um só tempo, sua fragilidade e sua potência. Segue menos como um conceito e mais como uma noção aberta à instrumentalização de moralidades e cálculos utilitários. Seu alcance e significações estão em disputa entre operadores, ativistas e pesquisadores.
1. Pesquisas empíricas são aquelas produzidas em estudos etnográficos, conjugando métodos e técnicas qualitativas e quantitativas, orientadas por um referencial teórico. Diferem de trabalhos de "pesquisadores nativos" (Muniz, Caruso e Freitas 2018) pois delimitam fronteiras sobre os engajamentos militantes (Becker, 1960). Estes apontam para a ideia de "compromisso" como um mecanismo socio-psicológico específico, expressando ações, interesses, oportunidades, moralidades em disputa e que resultam em reconhecimentos. 
Reflete uma arena de embate de forças que serve como um sensor dos avanços, estagnações e retrocessos da previsão e provisão de direitos ali na esquina.

Observa-se que diferentemente da produção europeia e a norte-americana, a literatura brasileira foi marcada pelo binômio violência versus direitos humanos (Adorno, 2001). Esta oposição, ora como premissa militante oculta, ora como juízo intelectual explícito, desdobrou-se em outras díades - Estado versus Sociedade, Polícia versus Cidadão. Isto favoreceu a constituição de narrativas persecutórias que encerravam disputas pela verdade, por exemplo, entre levantamentos de denúncias de violência estatal e relatórios de pesquisa. Favoreceu, ainda, a emergência de narrativas apofáticas que definiam pela negação a segurança pública, seus agentes e suas práticas estatais. Como consequência, assistiu-se o surgimento de explicações tautológicas dos fenômenos que se pretendia compreender. Ao invés de compreender a natureza coercitiva das organizações de força e suas implicações adjetiva-se e julga-se estes dispositivos de controle e regulação sociais como a priori perversos. A opção por esse paradigma se traduziu em uma lógica pendular. Tem-se uma constatação dedutiva que se antecipa aos fatos, cabendo às evidências empíricas o papel subordinado de ilustração comprobatória de um juízo moral prévio. Assim, procura-se "culpados", no caso as polícias, para a produção de violências institucionais. O contraponto a esse discurso produz narrativas do dever ser, tratando das mesmas instituições como as "garantidoras" de direitos humanos. Nos dois casos a empiria é desprezada, impedindo que se compreenda as instituições policiais, seus valores, seu funcionamento, seus atores enquanto realidades singulares e, por sua vez, como as relações se dão, se desenvolvem e podem, ou não, ser transformadas.

Nosso objetivo não é fazer um balanço da produção sobre a segurança pública e seus dispositivos de controle social, suas tendências ou os contextos de sua criação. Esse preâmbulo é um ponto de partida para situar como uma perspectiva estratégico-metodológica, orientada pela Antropologia, tem sido fundamental para a construção de nossos estudos empíricos sobre as relações entre sujeitos e instituições. Salientamos que nossa condição de pesquisadoras não é isenta e foi afetada, conforme proposto por Favret-Saada (2005), trazendo implicações epistemológicas que derivam de nosso lugar na produção de conhecimento nesse campo. Ao anunciarmos de que lado estamos é preciso falar que somos mulheres e já atuamos na gestão pública, o que nos faz conhecer o que se chama de "o outro lado" - o mundo da tomada de decisão e da ação - tão valorizado pelos operadores de segurança e pelo senso comum, que consideram o tema "masculino". Além disso, importa dizer que toda discussão de Direitos Humanos não foi feita para defender o Estado e com isso confinar-se na armadilha da oposição Direito do Estado versus Estado de Direito. Quando se pretende estudar as relações de poder, o Estado é apenas uma das suas formas primordiais de governo, na condição epistemológica de "nosso objeto". Há outras formas de governo que não se apoiam em estruturas burocráticas e arranjos institucionais orientados pela racionalidade legal e legítima de tipo weberiana. Assim, olhamos com estranhamento, inspiradas por Bourdieu (1996), os enquadramentos empírico-analíticos do tipo "quando se trata do Estado nunca duvidamos demais".

A pergunta que nos orienta é como construir uma abordagem multidimensional de um fenômeno empírico, sem estereotipar os sujeitos e as instituições que dele participam? Isso pressupõe pensar em múltiplas variáveis para que se possa compreender o diferente-singular no universo empírico, que delimita suas formas diversas ou a variabilidade de sua manifestação. Ao se analisar, 
por exemplo, as situações de conflito é fundamental considerar a pluralidade de fatores que concorrem para a sua existência diversa e sua expressão (Gluckman, 1987; Van Velsen, 1987). Sabemos que os fenômenos não operam necessariamente como se manifestam (Lévi-Strauss, 1976). A conflitualidade, talvez mais que qualquer outra dimensão, explicita o confronto entre os sujeitos distintos, os ditos e os feitos da vida social, e os modos informais e institucionais construídos para sua administração. Para compreender como são construídas as "ficções" do Estado (Radcliffe-Brown, 1970) que o tornam algo real, com vida própria, é necessário perceber que as instituições se atualizam em seu funcionamento cotidiano que, por sua vez, se faz por meio de embates intergrupais diante da heterogeneidade de sujeitos, valores, normas, dispositivos e rotinas que compõem as instituições da chamada máquina estatal e suas esferas de interlocução (Douglas, 1998).

Preocupação análoga à problemática teórico-metodológica dos estudos sobre o Estado e suas múltiplas vidas institucionais deve estar presente nas análises sobre os ativismos. Para definir o universo de pesquisa e recortar sua amostragem é preciso delimitar o que se entende por "garantias de direitos", explicitando o seu alcance discursivo e suas manobras políticas de sentido. No caso brasileiro, isto corresponde a delimitar quais e como são as instituições que se apresentam e operam neste registro. Implica também em problematizar a categoria cidadania, que aparece como insuficiente em si mesma exigindo sobrenomes ou qualificativos em suas construções científicas e políticas. Temse tantos adjetivos para a cidadania quanto as formas de tutela e expectativas militantes de mudança: "cidadania relacional", "cidadania regulada", "cidadania participativa", "cidadania inclusiva", "cidadania igualitária", "cidadania plena", "cidadania sacrificial", etc. (Muniz e Patrício, 2018).

Recentemente, passou-se a falar dos "cidadãos de bem", expressão que exemplifica como quando se fala em direitos há uma representação de que são uma conquista individual, uma espécie de bonificação que é concedida, ou não, a cada indivíduo ao longo de sua trajetória, em razão da aprovação de seu comportamento diante do Estado e no Mercado: "tem que fazer por merecer". Assim, ter direitos corresponde a "andar direito e nos conformes" para passar nas revistas continuadas dos agentes estatais e das diversas instâncias morais de autoridade. Há que "melhorar para ter melhoria", há que ser e estar do lado certo aos olhos dos dispositivos de controle e regulação sociais. A garantia de direitos é um "vale", um empréstimo ou adiantamento concedido pelos agentes - do Estado ou do Mercado, que só funciona para alguns. Uma das razões práticas das instituições estatais é operar como motor da universalização seletiva dos direitos, de suas garantias e de seu acesso, seja quando promove discriminação positiva sob o jargão compensatório da "inclusão afirmativa", seja quando produz discriminação negativa normalizando os processos sociais de exclusão. A cidadania sob tutela de uma adjetivação legitimadora lança mão de distintas razões de cor, etnia, classe, renda, gênero, orientação sexual, etc., como modo de gestão sobre pessoas e grupos sociais, conforme a ocasião.

A ideia de uma "tutela estatal" representa uma complexa tecnologia de governo (Foucault, 1990, 2009), característica da Administração Pública no Brasil (Souza Lima, 2014). Foi criada para dar conta dos "índios", uma identidade genérica que apagou as distintas etnias da história, subjugando-as. Esta engenharia sociopolítica faz das instituições estatais e de seus agentes os legítimos procuradores dos interesses das cidadanias "carente" e "vulnerável". Tem-se uma disputa pelo lugar de porta-vozes e pelo monopólio da representação política do "outro" diverso, da diferença desigualada junto ao terceiro setor 
(ONGs). Tem-se uma máquina política de transformação da diversidade em desigualdade natural e esta em diferença social substantiva, que requer um tratamento especial para sujeitos especiais. Aqueles sujeitos despossados de si por esta tecnologia hierárquica tutelar que (re) produz relações de sujeição e de dependência.

Analisar direitos tem a ver com a política em seu sentido pleno. Tem a ver com a atuação do Estado em uma abordagem ampla; com os modos de exercício de governo em um recorte específico; de que lado, nós pesquisadores, estamos diante uma perspectiva epistemológica crítica que reconhece a reflexividade como forma de inscrição na realidade das pesquisas em Ciências Sociais. Não se trata de tomar como ponto de vista a "letra da lei" tal como está nos marcos normativo-legais, e que faz do "dever ser" prescritivo uma métrica de aferição analítico-moral das realidades sociais sob intervenção das práticas de pesquisa. É ter como ponto de partida os conflitos entre "mundo da lei" e as "leis do mundo", e que faz do devir das práticas e da deriva das representações sociais uma pista para a compreensão das narrativas em suas disputas por hegemonia discursiva nas realidades sociais sob interferência das atividades de pesquisa.

Nesse sentido, falar de polícia corresponde a falar sobre modos de governar. Vigilância, disciplina e correção são parte dessa tecnologia de governo voltada para produção de controles espaço-temporais sobre populações e territórios. Falar de polícia é falar de um tipo de exercício de governo estatal ou não, público ou privado, legal ou ilegal, de fluxos de valores, pessoas, bens e serviços. É tratar de práticas de governo que atravessam e ultrapassam a economia política do panóptico. Isto porque se voltam para a gestão do movimento de coisas, do deslocamento de pessoas, da circulação de ideias. Uma expressão de governo itinerante e pervasiva, distribuída nas entradas, encruzilhadas, fronteiras e saídas dos grupos sociais. Um dispositivo móvel de gestão para produzir controles também móveis sobre as temporalidades e as territorialidades dos sujeitos. Um meio potencial e concreto de força para afirmar as distintas formas de cidadania e os contornos, mais ou menos inclusivos, do status quo do pacto político-legal. Um modo de gestão de policiamentos para atender aos fins das políticas de administração da mobilidade espacial e social.

Se polícia é um governo itinerante, se os policiamentos são controles móveis, se a segurança pública é a gestão da circulação em escala, não se tem como idealizar modelos estáticos, dedutivo-normativos para exercê-los e, menos ainda, para compreendê-los. A impropriedade do entendimento normativo e generalista da realidade pode ser compreendida por meio da alegoria jurídica brasileira do "poder de polícia". Inspirado em uma França totalitária setecentista (Sûreté, Sêcurité, Salubrité), o "poder de polícia" está definido no atual Código Tributário de 1966 e foi normatizado durante a ditadura militar. ${ }^{2}$ Sua amplitude tutelar-coercitiva corresponde a um "pode tudo" do Estado contra a sociedade. Consiste em um "poder delegado" a qualquer agente estatal em função de fiscalização e/ou de regulação e não apenas aos policiais (Kant de Lima e Miranda, 2012; Muniz, 2014; Miranda, 2015). Tal provisão normativoadministrativa do Direito do Estado contraria as previsões normativo-constitucionais que informam o Estado de direitos dos indivíduos. Tem-se, aqui, um confronto entre os supostos direitos de cidadania e os deveres das espadas que, no mundo do dever ser democrático, deveriam garanti-los. Este embate intencional entre formas de legalidade e suas táticas de legitimação favorecem à proliferação de inseguranças jurídicas tanto para os agentes da lei quanto para os indivíduos policiados. Suas manobras se manifestam no uso da imprevisibilidade decisória dos agentes de controle tutelar como um recurso 
particularizado de ruptura e reinauguração de rotinas. A regularidade nos encontros entre policial e policiado é ritualizada como uma constante reestreia. Neste espetáculo interativo, a incerteza e a desconfiança recíproca exigem um cálculo pessoal de múltiplos riscos segundo os marcadores sociais da diferença do sujeito que se depara as barreiras do controle social (Ceccheto, Muniz e Monteiro, 2018). Fica evidente o quanto é improdutivo um exercício de pesquisa que tome como categoria explicativa a chamada "cidadania". As pessoas se movimentam, na sua rotina urbana, há fluxos orientados por marcadores identitários, que delimitam o escopo da circulação, que circunscrevem os seus movimentos, suas resistências, seus silêncios e sua passividade.

Falar de "segurança, território e população", tal como problematizado por Foucault (2009) implica falar de sociedades e territórios em movimento, da segurança como circulação, das dinâmicas de poder que resultam em processos negociados de normalização, de geração de controle, enfim, da produção de governos e de suas tecnologias de gestão de fluxos de pessoas, coisas e valores. Implica falar, em contrapartida, da emergência de resistências, disputas e confrontos às tecnologias governamentais. Tudo isso deve ser pensado em termos de escala, afinal quão plural, diverso, múltiplo é o grupo com o qual interagimos durante uma pesquisa?

Então, toda e qualquer discussão sobre controle, no qual se inclui a discussão sobre tutela, precisa considerar a existência de formas cruzadas de regulação horizontal, vertical, transversal, mas jamais total (Muniz e Almeida, 2018). Se o monopólio do controle por instituições é uma ficção que produz efeitos (Miranda e Pita, 2020), melhor seria falar de uma pretensão pelo monopólio que se expressa em termos de disputas, sendo as "conquistas" um exercício permanente de instabilidade e fragilidade dos poderes.

\section{Um campo de experiências: achados da política pública para além dos "achismos"}

O intercâmbio de saberes e fazeres ao longo dos últimos cinquenta anos contribuíram para a construção de interlocução, produção e circulação de trabalhos entre pesquisadores, agentes públicos e ativistas, com efeitos ainda limitados de difusão dessa produção quando se trata do público em geral. Na ordem do senso comum, os conhecimentos científicos chegam às ruas muito depois, ou bem antes, dos atos experimentados sob o medo, do real da insegurança, dos riscos vividos, dos relatos das dores, das perdas e danos vivenciados. Como enfatizaram Weber (1982), Lévi-Strauss (1976) e Becker (2008), cada um ao seu modo, as representações científicas do mundo são antes representações sociais da realidade, categorias manobradas pelos modos distintos de compreensão e ação. Tem-se, na vida tal como vivida, uma economia política da significação. Tem-se confrontos, atravessamentos e mixagens entre conceitos e metáforas, entre juízos de fato e de valor. Tudo isto a serviço das inscrições, trânsitos e decisões cotidianas dos sujeitos no seu mundo e sobre o mundo dos outros. Este é o lugar político das ressignificações que põem em circulação, nas arenas de sentido, desvendamentos e reencantamentos da vida social produzidos pelos sujeitos diante de sua experimentação seletiva e desigual dos saberes e das práticas que ordenam sua rotina. A vontade de verdade das chamadas "teorias nativas" nas sociedades com Estado e de Mercado, revela o uso interessado, pragmático e particularizado da forma, da taxonomia e da retórica argumentativa do discurso científico. Alguma embalagem e algum recheio de verdade científica, a "verdade mais verdadeira", são indispensáveis como 
estratégias de legitimação nas disputas moral e política por autoridade, isto é, por poder-saber e poder exercer governo sobre os outros. Os hibridismos simbólicos entre saberes científicos e ordinários correspondem aos "achismos" do senso comum que servem como preciosos pontos de partida para se chegar aos pontos de vista expressos nos "achados de pesquisa". No caso do campo da segurança pública, eles apontam pistas sobre o modo como os conflitos são pensados e de que forma suas gestões são operadas.

A máxima "direitos humanos para humanos direitos" explicita uma concepção do direito como uma dívida apriorística a ser paga com a sujeição a uma forma exterior, hierárquica e particular de ordem. Revela-se, também, como uma ameaça jurídica latente feita por manifestações legais ou ilegais de autoridade. Há que fazer por merecer, mostrar que anda direito e à direita, para obter um voucher de direito humano com prazo de validade até a próxima quitação moral das obrigações. Explicita-se um programa de milhagens político-jurídicas cuja questão central é quem conquistou o poder-direito de por a régua da medição dos níveis de humanidade dos sujeitos em constante avaliação? Quais são as métricas desta régua e sua utilidade? A governança do direito humano consistiria na gerência de uma justiça substantiva, direta, parcial e mais próxima do imediato, ali nas esquinas. A incerteza e a insegurança substituiriam as chamadas garantias legais e a previsibilidade das normas jurídicas. Como os julgadores de hoje podem ser os julgados de amanhã, há que buscar tutelas e protetores e, com isso, fazer parte de alguma clientela para conseguir que a desigualdade meritória possa funcionar a favor do apadrinhado de ocasião. A expressão "bala perdida" usada para classificar supostas vitimizações acidentais nos confrontos entre policiais e domínios armados (Miranda e Muniz, 2020), especialmente nos territórios populares, vai além de negar o conflito e naturalizar a sua solução violenta entre sujeitos desiguais em direitos. Ela expõe um cálculo político que atribui pesos variados às vidas humanas. Bala perdida seria uma bala da polícia desperdiçada com um alvo desimportante, que "morre para nada", e que poderia ter matado quem mais merece com menor custo para o Estado (Muniz e Almeida, 2018). Nesta política atuarial de gestão de vidas precárias há méritos (uma condecoração pelo reconhecimento social positivo) para quem mata no "cumprimento do seu dever" e há merecimentos (uma acusação pelo reconhecimento social negativo) para quem morre, que mereceu ser morto e "entrar para estatística" (Cecchetto, Muniz e Monteiro, 2020). Os precarizados permanecem com o status quo que tinham em vida: apenas "um número, mais um". A "bala perdida" policial ineficiente desponta como "bala achada" política eficaz, aquela bala que procura e acha os corpos dos matáveis, os corpos negros, pobres e periféricos. Por fim, estes modos de gestão resultariam da existência ou da "falta de vontade política" do governante. Aqui, evidencia-se dois elementos importantes da nossa compreensão ordinária do fazer da política. Uma visão personalizada do exercício de governo centrado na figura do dirigente e uma concepção volúvel e descontínua da política pública. Como diz o ditado popular, "vontade é uma coisa que dá e passa". Assim, a existência de uma política seria uma demonstração de "boa vontade do governante" e sua duração um capricho voluntarioso que reduz a dimensão pública ao lugar de plateia e que passa ao largo da institucionalidade estatal. Dramatiza-se um confronto entre o "pode da vontade governamental" e o "não pode da burocracia estatal". Quando a política é somente o próprio político, suas intervenções têm a provisoriedade de um "experimento", de "uma experiência", de "um projeto piloto" com prazos publicitários e validades eleitorais. 
Pensar sobre as condições de elaboração de pesquisas empíricas, de formulação teórica e de constituição de espaços de debate implica em encarar as tensões e os desafios em contextos de transformações sociais, no Brasil. Corresponde a um engajamento crítico e uma reflexão politizada sobre as formas de produção do conhecimento antropológico e suas implicações no que tange às relações constituídas com os grupos com os quais se interage. Consiste em realizar uma Antropologia da própria pesquisa antropológica em curso, desvelando e problematizando os lugares de falas dos participantes e suas tecnologias discursivas no contexto da pesquisa. Implica em apreciar os limites e alcances das observações participantes e das participações observantes, bem como os seus efeitos, consequências e repercussões para além do campo acadêmico.

Howard Becker, no artigo “De que lado estamos" (1977), discutiu a relação entre fazer pesquisa e ser militante. Mas é importante que se diga que, no campo da segurança pública e direitos humanos, estes endereçamentos e suas transações nem sempre estão evidentes para os sujeitos. A sua configuração político-prescritiva sobrepõe ou mescla as premissas morais, que atravessam os saberes e práticas sobre controle social e direitos, com os pressupostos científicos construídos a partir da pesquisa sobre este mesmo universo. A negociação entre os papéis de militante e pesquisador(a) requer explicitação das posições políticas e rigor metodológico nos procedimentos de seleção, compilação e tratamento das evidências empíricas. Contudo, assiste-se, por vezes, a um embate entre "achismos" - você acha isso e eu acho aquilo. Explicita-se, neste caso, uma militância que se faz ou se quer oculta, que não se pensa como tal, que não distingue sua "opinião" de conhecimentos construídos através do consenso científico. A leitura de Becker ajuda a pensar os dilemas políticos, epistemológicos e éticos na pesquisa-ação a partir do conflito. A dimensão empírica mostra que a realidade não é homogênea, revelando os esquemas interpretativos em disputa. A dimensão constituinte da vida social expressa como as identidades, suas representações e mecanismos de legitimação se constroem nos enfrentamentos pela busca de pertencimento e reconhecimento. Ambas as dimensões são vividas e confrontadas pelo(a) pesquisador(a) militante, exigindo posicionamentos críticos e reflexivos.

Outro aspecto fundamental proposto por Becker é uma de suas explicações sobre o processo de interação social, em especial, aquelas referentes à sanção social e ao controle social. Ele critica algumas teorias, que pressupõem que as pessoas ajam consistentemente e coerentemente, porque os desvios ao padrão seriam punidos. Tais teorias explicam comportamentos desviantes por um processo circular: a pessoa comete uma infração menor, é alienada da sociedade, e volta a cometer infrações cada vez mais graves. O erro está em lidar de modo individualizado com o conflito. Outro equívoco é crer que o controle social se estrutura apenas pela internalização de regras. Nenhuma dessas teorias oferece uma explicação sobre como as pessoas escolhem um dentre os muitos públicos com os quais interage. Isto porque acredita na existência de valores culturais homogêneos e universalmente aceitos como formadores de comportamentos uniformes. Só que nenhuma sociedade é homogênea e, consequentemente, nenhum comportamento é uniforme. Não há neutralidade efetiva dos valores e práticas, portanto, as pessoas fazem escolhas a partir de situações concretas que representam alternativas práticas, percebidas como válidas, em relação aos contextos nos quais vivem. Voltando a Simmel (2011), é dizer: as sociedades se instituem pelo conflito e pela sua gestão que informam os processos de constituição da diversidade e da unidade, os dispositivos de coesão e coerção sociais, os processos decisórios dos sujeitos em seus registros identitários. 
3. O termo se distingue de uma antropologia aplicada, com seu viés reformista (Bastide, 1979), e de uma antropologia implicada, associada à ideia de "intervenção", proposta por Didier Fassin (2008).

4. Entendemos por controvérsia "as manipulações de diversas formas discursivas por diferentes agentes" (Montero, 2012). São inserções plurais na vida social que influenciam o modo pelo qual a percepção sobre os fatos se visibiliza no espaço público, constituindo-se em problemas sociais (Cefaï, 1996).

5. A ideia de rede é fundamental para compreender como as relações entre pessoas se constitui, permitindo identificar as (as) simetrias. Permite analisar o protagonismo de lideranças, destacando como as interações são múltiplas e ocorrem num dado território, sem necessariamente resultar em laços de coesão (Barnes, 1954).
Vê-se que as relações entre a pesquisa antropológica e a ação política, em suas múltiplas formas de manifestação, resultam numa política da e na Antropologia. Esta se produz "enredada" (Miranda, 2019) ${ }^{3}$ pela definição dos recortes teóricometodológicos, dos envolvimentos políticos na esfera pública, na escolha de modos controversos ${ }^{4}$ para lidar com problemas sociais que se tornam públicos.

Assim, a Antropologia tem contribuído para a produção de conhecimento acadêmico, e para as políticas públicas, mas não num formato de modelos para intervenção generalistas e exteriores às realidades sobre as quais se atua (Pita e Miranda, 2015). Trata-se de uma Antropologia em ação, que se constitui a partir de redes ${ }^{5}$, orientada por uma agenda democrática, progressista e includente que valoriza a diversidade como pressuposto. Uma Antropologia que sempre teve lado, sem jamais perder o senso crítico e o interesse por uma abordagem interdisciplinar, sem medo dos números - a mal falada estatística.

A famosa "Escola de Manchester" ensinou como fazer estudos situacionais (Gluckman, 1987) e de que forma construir argumentos generalizáveis a partir deles. Também ensinou como analisar quantitativamente as redes sociais como um recurso auxiliar às observações de campo (Mitchell, 1987), que se mostrou favorável para explorar as relações interpessoais, controlando a variabilidade destas ações em seus contextos, como estratégia para evitar que a Antropologia se tornasse apenas a biógrafa "das sociedades isoladas" (Nadel, 1951, p. 6), produtora de narrativas literário-jornalísticas dos testemunhos nativos.

Ressalte-se que a quantificação das qualidades e qualificação das quantidades são movimentos analíticos instituintes de um campo de conhecimento que nasce contrastante (os outros de nós outros) e comparativo (o nós dos outros). O papel dos métodos quantitativos é auxiliar ao processo de descrição orientada pela teoria. Suas contribuições, sobretudo em estudos de larga escala, são explicitar as ausências, indicar regularidades e variabilidades, apontar possíveis mudanças de comportamento, mapear e classificar categorias. A Antropologia em seus trabalhos de campo e suas trajetórias teóricas não só fez uso de mapas, gráficos, tabelas, borderôs, e demais expedientes de representação visual, gráfica e cartográfica, como também lançou mão das chamadas amostragens indicativas e estatísticas para circunscrever seu universo de pesquisa.

A dimensão empírica, quando se trata de relações entre sujeitos e instituições e/ou de instituições entre si, aponta confrontos, disputas entre o dever ser, o poder ser e o querer estar. Por isso não se pode acreditar que há algum discurso neutro. Todas as narrativas sobre si, o outro e o mundo são discursos de poder, que expressam um modo singular de pensar sobre e do Estado - para que ele serve? Enunciam um modo de exercício do que deveria ser Estado e/ ou um governo.

É, pois, preciso olhar com olhos, de fato, antropológicos a política pública. É preciso romper com abordagens ilusionistas que se satisfazem em recortar o funcionamento ou não das políticas públicas no genérico. É fundamental compreender como obram na prática, em especial, quando são tecnologias de governo voltadas para dar conta da diversidade, seja em sua expressão afirmativa, seja em sua expressão anuladora. 


\section{Como as políticas públicas afetam os sujeitos?}

A crescente demanda por antropólogos(as) está associada a uma reconfiguração do mercado de trabalho e, consequentemente, a emergência de novos papéis. Além da produção de estudos científicos estrito senso, há um mundo de pesquisas "aplicadas", pareceres técnicos, perícias, levantamentos temáticos demandados por grupos sociais, coletivos organizados, governos, ONGs e empresas. Os "especialistas" que atuam no campo de políticas públicas desempenham distintas funções tais como consultores, analistas, funcionários técnicos e assessores. As responsabilidades que lhes são atribuídas precisam colocar em xeque o método clássico da observação participante e do trabalho de campo de longa duração. Afinal, este é o universo de uma Antropologia em ação por sobre as intervenções da política em ato. Daí questionar quais são os limites éticos e políticos que o(a) antropólogo(a) enfrenta para a produção de conhecimento que resultam em intervenções nos processos sociais, com impactos nas identidades individuais e coletivas?

A construção de metodologias inovadoras está orientada pela necessidade imperiosa de encontrar pontos convergentes que possibilitem "traduções" entre linguagens e modalidades de trabalho. A primeira questão a destacar quando se trata de atuar nas, ou analisar, políticas públicas está relacionada ao desafio de pensar sobre como as formas de intervenção político-institucional em áreas específicas são resultado de um trabalho conjunto de pesquisa. Isto significa reconhecer que a produção de conhecimento resulta sempre de negociações entre universidades, organizações estatais, ONGs, empresas, etc., que possuem interesses, ambições e temporalidades distintas na produção de seus saberes e espacialidades diversas de ancoragem de suas interações e trocas.

Outro aspecto importante é que esses movimentos podem ser estáveis ou instáveis, podem ser precários, provisórios, ou ganharem permanência, em função das perspectivas e oportunidades conjunturais. Não basta delimitar o Estado por meio do que é aparente, visível e mais acessível, como suas previsões normativas e estrutura administrativa. Tem que conhecer os saberes que fazem o funcionamento da política na prática e que põem em operação os marcos normativos e as provisões organizacionais. Para dar conta desta realidade, é fundamental apreender o confronto entre as regras, o enfrentamento entre valores, e destes entre si. É indispensável buscar os conflitos, as ambivalências, compreendendo a "linguagem do Estado" expressa por suas estatísticas oficiais (Miranda e Pita, 2020; Pita e Miranda, 2015).

Quando se analisam quais são as práticas convencionais dos pesquisadores nesse campo, nota-se que há uma valorização dos que são "práticos", por sua capacidade rápida de diagnóstico e produção de recomendações que se conformam às tradições e dinâmicas de instituições e burocracias que deveriam analisar. Essa "cultura das consultorias" (Pita e Miranda, 2015) pouco ajuda a fortalecer um campo de estudos sobre políticas públicas. Por uma simples razão: há um produto sob demanda remunerada a ser feito e entregue no prazo, sob certas exigências instrumentais e contratuais. Por uma razão complexa: nas atividades de consultoria, por exigências do tipo de trabalho, as fronteiras entre as dimensões do monitoramento, avaliação e análise de políticas públicas tendem a ser mais fluidas. Paga-se um produto, esperando obter um pouco de todos. Em casos extremos e absurdos, esse tipo de trabalho ajuda a produzir caricaturas do real, por exemplo, ao exagerar nas descrições do problemas identificados - desvios, violações e violências - apenas legitimar a existência de uma dada política. Isto resulta da interpretação de um trabalho 
especializado que ignora o mundo vivido, as localidades onde os fenômenos acontecem e, sobretudo, como os sujeitos sociais são resultado de trajetórias concretas que correm o risco de serem anuladas, invisibilizadas por discursos anódino ou alarmistas, ditos "neutros e técnicos".

Criam pseudo-lugares de fala e lugares de silêncio ao hiperdimensionar discursos nos quais se valorizam os marcadores sociais, mas não reconhecem, por exemplo, que a manipulação de vítimas, a saturação de sua exposição continuada e o sequestro de sua palavra nas reencenações de seus testemunhos, têm graves impactos nas vidas destes sujeitos. Ao se expor infinitamente no espaço público (a polícia, o tribunal, a mídia), a vítima é desestabilizada emocionalmente, precisa contar uma história trágica, um drama, que será revivido infinitamente sem que se guarde respeito, discrição, pela sua identidade. Corpos mutilados são expostos em documentos e vídeos, como se não pertencessem ao sujeitos reais. Muitas vezes a única proteção ao voyeurismo do suplício e humilhação deste sujeito "outro" é a famosa tarja preta nas fotos.

Note-se como o assujeitamento pode se manifestar em políticas públicas que, em tese, estão ali para proteção dos direitos humanos. Observe que a performance panfletária da reivindicação do reconhecimento do "sujeito de direitos" de quem tem menos capitais sociopolíticos se perverte em "sujeito (às ameaças) ao direito" de quem te mais capitais político-econômicos. A destituição do lugar do sujeito por meio de seus despachantes, porta-vozes, representantes etc., pode até servir para produzir uma tutela mais simpática aos olhos militantes. Mas estruturalmente segue como uma política que trata de um sujeito abstrato que se pode domesticar, docilizar, enfim, destituir de soberania. Vemnos à mente os casos de estupro, de violência sexual, nos quais o corpo da mulher é mostrado, apresentado em partes e naturalizado em salas de aula de perícia forense e nos fóruns jurídicos de defesa dos direitos das mulheres.

Essa tecnologia é uma construção político-jurídica do Estado Brasileiro, num diálogo entre Direito e Medicina e seus mecanismos classificatórios que constituem um mundo do dever-ser orientados por juízos morais, que normatizam e hierarquizam os grupos. Mas esse processo, como argumentamos, não é monolítico. O funcionamento do Estado é plural, opera em tempos diferentes: o Legislativo tem uma temporalidade própria de funcionamento, o Judiciário outra e o Executivo outra distinta. Estes tempos decisórios e dos fluxos de suas engrenagens não são convergentes. Por isso mesmo é preciso articular, acordar, enfim, construir e fazer uma política pública - declaratória. Dentro do próprio Poder Executivo as diversas instâncias possuem tempos distintos ao longo de seus processos de trabalho. Há que negociar, fazer a política interinstitucional. A delegacia tem seu tempo e seu ritmo de produção completamente distintos da promotoria. E por aí vai. Daí a importância da pesquisa empírica para a compreensão do que é comum a partir do entendimento do que se faz singular. A construção do olhar antropológico é antes de tudo um enquadramento sobre as formas políticas de produção do conhecimento nas Ciências Sociais. O rigor reflexivo e o compromisso ético na pesquisa, nas relações com os sujeitos, busca explicitar os exercícios de poder nestas interações para submetê-los à crítica e aos critérios de cientificidade sob consenso. Não é, portanto, pela ocultação ou esquecimento das expressões de poder nas atividades de pesquisa e suas implicações que se afastam os fantasmas da ideologização ou da censura sobre os dados. Inversamente e fazendo as realidades falarem em seus próprios termos como nos ensina a tradição antropológica. 


\section{A multidimensionalidade e a situacionalidade dos fenôme- nos.}

A reflexão teórica é, portanto, a base da construção de qualquer metodologia de pesquisa. O que pretendemos sustentar nesse artigo é que em pesquisas que envolvam segurança, criminalidade, violências e ativismos devemos fazer escolhas que priorizem a multidimensionalidade e a situacionalidade desses fenômenos. Esse campo temático amplo significa falar do 'estar' e do 'ser' em distintos contextos, numa afirmação continuada da pluralidade de sujeitos. A perspectiva é situacional porque o 'ser' foi construído na prática, no mundo real do dissenso, no qual o processo de produção do consenso se dá pela interação de sujeitos contraditórios que confrontam e negociam seus ditos e seus feitos nas interações. É necessária essa contradição porque ela nos move a construir os tais consensos provisórios.

As pessoas têm temporalidades e mobilidades distintas, que são orientadas por uma dada "realidade", que sempre é classificatória. As inscrições nas linguagens acadêmica, social e política resultam de embates entre sujeitos que trazem seus marcadores sociais nas suas negociações de pertencimento e reconhecimento. Assim, pesquisadores e interlocutores estão marcados por moralidades. Quando se trata do campo do Direito não se pode esquecer que ele se confunde com o lugar de construção do Estado, justamente porque é operador normativo do fazer político. Por isso não pode ser pensado como asséptico, já que é uma expressão da instrumentalidade política, que produz o dever ser sob o signo da pretensão dos monopólios.

Tomaremos como referência para exemplificar nosso argumento o trabalho que foi realizado no âmbito do projeto de Pesquisa e Desenvolvimento (P\&D) “Desenvolvimento de metodologia 'Mapa de Percepção de Riscos' para a análise da variável socioeconômica violência no diagnóstico de perdas não técnicas de energia nos municípios de São Gonçalo e Duque de Caxias (RJ)", 6 financiado pela Agência Nacional de Energia Elétrica (ANEEL), realizado em parceria com a empresa ENEL S/A, cujo objetivo era o desenvolvimento de um método de pesquisa para identificar as situações sociais de violência que afetavam o trabalho regular de medição de energia elétrica ${ }^{7}$, que pudesse ser replicável a qualquer distribuidora de energia (Miranda, Muniz e Corrêa, 2019).

Chamamos de Mapas de Percepção de Risco a ferramenta analítica construída numa abordagem dinâmica e multifatorial das noções de violência e risco, tal como a empresa classificava, e o conceito de domínio armado formulado por nós (Miranda e Muniz, 2018). A empresa pressupunha que o furto de energia8 era um fenômeno criminal disseminado pelos municípios de São Gonçalo e Duque de Caxias (RJ). Relatava que a dificuldade de prestação de serviço somente ocorria em áreas, em situação de vulnerabilidade social, controladas por traficantes ou milicianos. Consideramos que era necessário desvincular a relação causal entre o furto de energia e a pobreza, que estava presente na forma pela qual a ANEEL realiza o mapeamento do fenômeno em todo o país. ${ }^{9}$

Tomou-se como hipótese que a definição de áreas, classificadas como de maior ocorrência de furto de energia coincidiria, por exemplo, com o funcionamento de um mercado de oferta ilegal de serviços essenciais e comerciais (energia elétrica, gás, internet, TV a cabo, entrega de correspondências, água, transporte público ilegal, etc.). Este se apoia em uma rede de operadores articulada às ameaças e venda de proteção, gerida e disputada por grupos criminosos que exercem o controle armado de territórios, por meio do qual regulam o acesso
6. Termo de cooperação $n^{\circ}$ 23069.002643/2016-74 (ENEL / Fundação Euclides da Cunha - FEC/ Universidade Federal Fluminense - UFF), ratificado pelo Conselho de Ensino, Pesquisa e Extensão (Resolução n²10/2016)

7. No Brasil a energia elétrica é um serviço público essencial, prestado por sociedades empresárias em $2 / 3$ da produção nacional, a quem o Estado transfere, mediante concessão, a exploração comercial, caracterizando uma relação de consumo, sujeita às normas do Código de Defesa do Consumidor.

8. Em levantamentos sobre furto de energia financiados pela ANEEL, identificou-se que o foco está direcionado à compreensão do comportamento do consumidor, mas não à análise de obstáculos que afetam a realização das práticas de medição motivados pela criminalidade violenta.

9. Analisou-se a consistência da variável "violência", utilizada na metodologia de tratamento regulatório para as perdas não técnicas de energia (Nota Técnica no 106/2015 - ANEEL), que se baseia nos dados provenientes do DATASUS. 
e a circulação de pessoas, bens e serviços. Seria, portanto, a existência de um governo autônomo criminal que exerce a gestão político-administrativa do território regulando o seu mercado ilícito, que impediria os funcionários de realizar as marcações, medições, reparos, etc. Isso não quer dizer que em áreas sem domínios armados não existe furto de energia. O que se identificou foi que esse furto corresponde a uma prática lucrativa que possui expertise e que requer níveis de competência técnica, consentimento e vigilância de distintos agentes que atuam, de alguma forma, com a oferta (i)legal de energia elétrica. Corresponde a uma prática muito mais persuasiva, que envolve performances diferenciadas do que se imaginava. Isto nos levou a afirmar que o consumo de energia na favela não é de graça, como muitos atestam, os moradores pagam pela energia que consomem, ainda que de maneira informal e impositiva.

Optou-se por uma abordagem multimétodo, que se caracteriza pela integração de abordagens quantitativas e qualitativas. Tal escolha ocorreu porque a violência é um fenômeno dinâmico, por isso quanto mais convergentes forem os diferentes tipos de dados e/ou técnicas, mais consistentes serão os resultados da pesquisa:

》 Análise georreferenciada de dados de diferentes fontes oficiais;

» Análise de relatos dos funcionários sobre o próprio trabalho e sobre a criminalidade violenta, a partir de entrevistas em profundidade, visitas guiadas, grupos focais e construção de mapas mentais. As mesmas técnicas foram aplicadas aos moradores e profissionais de segurança, que vivem/atuam na região estudada;

" Pesquisa de vitimização laboral - relatos diretos sobre a expectativa de vir a ser vitimado e a ocorrência de vitimização, associada à construção da "reputação" do lugar (é visto como perigoso, por conta da memória de eventos ocorridos) e como esta afeta a percepção de risco.

As situações de risco identificadas e analisadas na pesquisa eram essencialmente espaciais (Figuras 1 e 2), já que a pergunta originária, que motivou o desdobramento das demais análises, foi compreender a relação entre as "perdas não técnicas", registradas pela distribuidora de energia elétrica, e a dificuldade de acesso dos funcionários, nos chamados "polígonos de risco", desenhados intuitivamente pela instituição.

A partir da definição de "polígonos de risco" pela empresa, a equipe realizou testes de variáveis. Os dados oficiais indicavam a presença de fatores de risco em todo o território dos municípios pesquisados. Fez-se, então, necessário esclarecer que o fenômeno designado como "domínio armado" não está limitado apenas a essas áreas. Por se tratar de um fenômeno que envolve disputa e controle armados de territórios, ele ultrapassa as regiões analisadas na pesquisa. A opção pelo conceito de "domínio armado" possibilitou analisar as dinâmicas de vigilância e controle armado do território, contemplando aspectos de sociabilidade em áreas controladas pelas milícias e/ou pelo tráfico de drogas. Permitiu compreender como o exercício ilegal de um governo não estatal impacta no oferecimento de outros serviços públicos e de comércio nessas mesmas áreas.

Uma constatação importante é que a atuação dos domínios armados nem sempre se traduz em homicídios - dado que orienta o índice produzido pela ANEEL, uma vez que contraria a racionalidade das práticas clandestinas eliminar o consumidor e o técnico reparador dos serviços ilegais. Por isso, é mais produtivo privatizar a segurança pública (venda de proteção comercial e residencial) e outros serviços urbanos, a partir da intimidação e ameaça, 

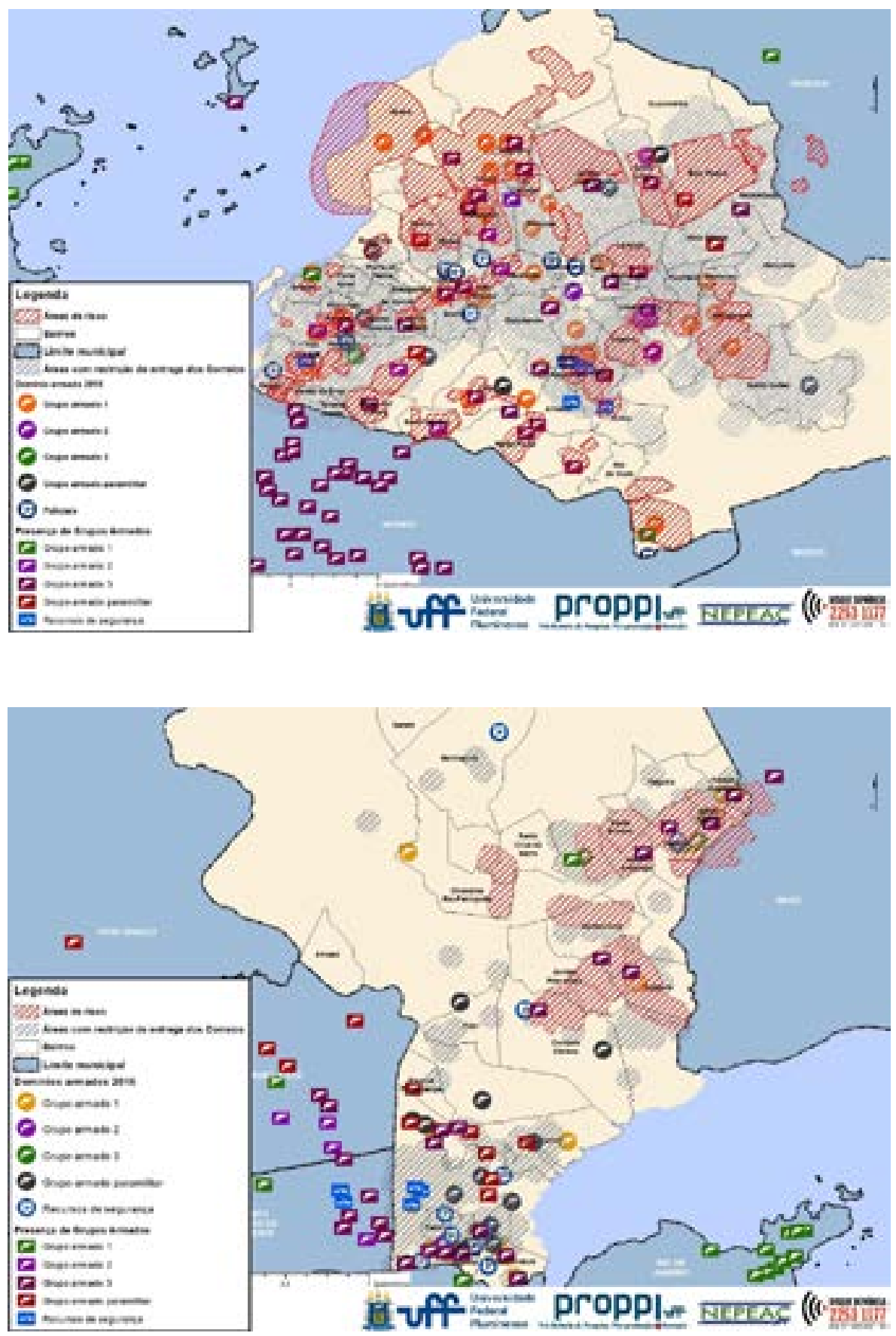

assegurando um fluxo de mercadorias ilegais administradas por eles, numa estratégia política de assegurar monopólio no mercado. É assim que tem atuado as milícias no Rio de Janeiro, como um tipo sui generis de prestação de serviços, constituindo um mercado de trocas informais e ilegais, que explora o trabalho dos prestadores de serviços das empresas, que possuem um knowhow singular.

Conclui-se, portanto, que a prática do "gato" de luz (ligações clandestinas de energia) está organizada e estruturada através de um mercado informal/ilegal - cujo funcionamento é elaborado e reconhecido localmente pelos moradores, considerado eficiente e prático, com alto custo-benefício se comparado aos serviços oferecidos legal ou formalmente.
Figura 1 - Mapa de Percepção de Riscos - São Gonçalo

Figura 2 - Mapa de Percepção de Risco Duque de Caxias 
Um aspecto fundamental a ser compreendido nas relações sociais que engendram o furto de energia como uma dimensão mercadológica importante. Nela se combinam a circulação de diferentes práticas, comportamentos e bens que estabelecem oportunidades de negócio. O furto de energia não é praticado apenas por clientes aleatórios, que decidem furtar e fazer uma ligação clandestina de energia em sua residência ou comércio. Ao contrário, o que se observou foi que, a instrumentalização para os desvios de energia está associada ainda às oportunidades pelo ambiente de trabalho das empresas. Ou seja, a forma de terceirização praticada pelas empresas que prestam serviço à ENEL faz com que os funcionários terceirizados, com vínculos trabalhistas precários e elevado nível de rodízio entre as prestadoras de serviço, recebam baixa remuneração e desfrutem de conhecimento sobre as tecnologias disponíveis subutilizado pelas empresas. A conjunção entre tecnologia, baixa remuneração, disponibilidade de mão de obra especializada e domínio armado tem possibilitado a formação deste mercado informal. Há que se destacar ainda que esses funcionários trabalham, muitas vezes, junto as outras concessionárias de energia. Essa circulação por empresas faz com que a expertise seja compartilhada. É assim que surge a identidade associada a esses prestadores de serviço, nas favelas, como "Gateiros", aqueles que realizam as ligações de furtos de energia. Salienta-se, porém, que ao prestar esses serviços, muitas vezes o fazem coagidos pelo tráfico ou milícias.

Ao realizar o trabalho de campo foi possível observar que existe uma diferenciação entre os grupos armados de regulação do acesso dos funcionários da ENEL nas áreas pesquisadas. Segundo um técnico a "milícia" e o "tráfico" atuam de formas diferentes, ambos são igualmente "perigosos", mas a abordagem para impedir os desligamentos é distinta. Na "área da milícia", o próprio "miliciano" fala com o "técnico" sobre o serviço que está sendo desempenhado. $\mathrm{Na}$ "área do tráfico", além do "traficante" ostensivamente armado, todo "morador" usa de seu pertencimento a uma "área de risco" para ameaçar o "técnico" com represálias e "você não sabe quem é envolvido ou não". A ameaça parece mais difusa.

O convívio obrigatório e inevitável da população das favelas com os grupos armados que atuam no seu território tem sido interpretado como cumplicidade por setores da sociedade. Tal fato resulta que as instituições, do Estado ou não, vejam os habitantes das favelas como isolados, configurando um processo de segregação socioespacial pela precariedade econômica e pela discriminação "racial", numa "superposição de vulnerabilidades" que restringe o acesso dos moradores das favelas à cidade (Fridman, 2008, p. 81).

Outra conclusão foi a de que a prática do "gato" não pode ser considerada resultante de uma relação direta com a pobreza, como pressupunha de algum modo a metodologia da ANEEL. Configura-se na construção do mercado de oferta do serviço de energia e pela fórmula da composição tarifária, que engendra um círculo vicioso, "quanto maior a tarifa, maior a procura pelos "gatos", que influenciam no reajuste da tarifa, que geram aumento da inadimplência, e assim sucessivamente" (Yaccoub, 2011, p. 3).

Compreender a dinâmica do domínio armado e sua relação de causa e efeito sobre os eventos criminosos e violentos, permitiu-nos identificar o impacto desta forma de autoridade sobre a reputação do lugar e a delimitação dos riscos vivenciados pelos prestadores de serviços que enfrentam de perto o poderio econômico dos grupos armados. A regulação da oferta de luz está diretamente relacionada ao controle territorial, que afeta à população residente 
silenciada pelas armas. A energia elétrica, além de um direito essencial, é um recurso central que movimenta a reprodução dos grupos sociais nas regiões de infraestrutura social e urbana precárias. Como se diz, "na favela tudo é luz", através dela os moradores têm acesso a outros bens, como a água, e de consumo, que possibilitam melhoria na qualidade de vida e inserção no estilo de vida urbano. A existência de um mercado ilegal de energia regulado pelo domínio armado é mais uma fonte de cobranças de taxas ou "impostos informais" (Muniz e Proença Jr, 2007). Foi com estas considerações em mente que discutimos com a empresa como delimitar espacialmente as áreas de risco, sem, no entanto, estigmatizá-las ainda mais.

A confecção da pesquisa de vitimização laboral corroborou a riqueza de informações trazidas pelo trabalho qualitativo, com a demonstração em porcentagem das situações de vitimização que os agentes enfrentavam, os indícios de domínio armado (Tabela 1). A amostra de funcionários foi de 555 para as duas localidades, dos quais $71 \%$ que atuava no polo Duque de Caxias e $80 \%$ no polo São Gonçalo foram vítimas de ameaça, coação, agressão ou roubo, que se revelam de formas distintas.

Tabela 1: Sentimento de insegurança e percepção de risco - indícios de domínio armado

\begin{tabular}{|l|c|c|}
\multicolumn{1}{|c|}{ Indícios } & São Gonçalo & Duque de Caxias \\
\hline Barricadas na rua & $90,7 \%$ & $92 \%$ \\
\hline Ameaça de traficantes & $87,6 \%$ & $81,7 \%$ \\
\hline Ameaça de milicianos & $0,8 \%$ & $5,0 \%$ \\
\hline Tiroteio & $84,2 \%$ & $82,2 \%$ \\
\hline
\end{tabular}

Fonte: Relatório Descritivo da Pesquisa de Vitimização Laboral

Apesar das diferenças entre os municípios constatou-se uma similaridade das repostas em relação às dificuldades de se executar uma ordem de serviço nas regiões que atuavam, que era apresentada com diferentes situações em termos de acessibilidade e circulação para execução dos serviços. Os trabalhadores podem ser expostos às disputas entre os grupos armados e/ou assistirem como testemunhas silenciosas e passivas as violações praticadas contra moradores e frequentadores destas localidades. Eles experimentam um estado continuado de alerta diante da possibilidade do risco, que é percebido como iminente quando se veem no meio de uma troca de tiros, por exemplo. Seu saber prático os orienta a seguir suas rotas de trabalho sondando, todo momento, com moradores, "olheiros", "soldados" do tráfico, comerciantes e quem mais se dispuser a ajudá-los, sobre a possibilidade de prosseguir e cumprir o serviço demandado ou retornar à empresa o mais rápido possível, cancelando a atividade prevista, sem ser descontado por isso.

Pode-se afirmar que o risco de ser vitimizado e as vitimizações produzem nesses trabalhadores um estresse análogo ao identificado em pesquisas de vitimização envolvendo policiais. Entre estes a gestão de riscos é estruturante das condições laborais, ambientais e relacionais. A inovação do projeto, a partir de uma demanda de uma empresa, permitiu que se questionasse os modos de gestão estatal e empresarial sobre o furto de energia, desvelando complexas teias de um mercado que segue regulado pela exclusão e por disputas por monopólios. 


\section{Financiamento:}

Enel/Aneel; CNPq

\section{Biografia}

Ana Paula Mendes de Miranda: Doutora em Antropologia (USP); Professora do Departamento de Antropologia, dos Programas de Pós-graduação em Antropologia e Justiça e Segurança (UFF); Pesquisadora do INCT-Ineac; Bolsista de Produtividade do CNPq; Coordenadora Adjunta dos Programas Profissionais em Antropologia/ Arqueologia - CAPES; Líder do diretório de pesquisa (CNPq) “Grupo de Estudos em Antropologia Política e Conflitos”.

Jacqueline Muniz: Doutora em Ciência Política (IUPERJ); Professora do Departamento de Segurança Pública (DSP/IAC-UFF) e do Programa de Pós-graduação em Justiça e Segurança (PPGJS/UFF). 


\section{Q Referências Bibliográficas}

"Adorno, S. (2001). Monopólio estatal da violência na sociedade brasileira contemporânea. Em S. Miceli (Org.). O que ler na ciência social brasileira (1970-2002), pp. 167-207. São Paulo: Anpocs.

» Barnes, J. (1954). Class and Committees in a Norwegian Island Parish. Human Relations, 7(1), 39-58. doi: https://doi.org/10.1177/001872675400700102

» Barreira, C. e Adorno, S. (2010). A violência na sociedade brasileira. Em C. B. Martins y H. H. T. S. Martins (Orgs.). Horizontes das ciências sociais no Brasil, pp. 303-374. São Paulo: Barcarolla.

》Bastide, Roger. (1979). Antropologia Aplicada. São Paulo: Editora Perspectiva.

" Becker, H. S. (1960). Notes on the concept of commitment. The American Journal of Sociology, 66(1), 32-40. doi http://dx.doi.org/10.1086/222820

》 Becker, H. S. (1977). Uma teoria da ação coletiva. Rio de Janeiro: Zahar.

"Becker, H. S. (2008). Segredos e Truques de Pesquisa. Rio de Janeiro: Jorge Zahar Editor.

" Bourdieu, P. (1996). Razões práticas: Sobre a teoria da ação. Campinas: Papirus.

"Bourdieu, P. (2008). A Economia das Trocas Linguísticas. O que falar quer dizer. São Paulo: Edusp.

" Campos, M. e Alvarez, M. (2017). Políticas públicas de segurança, violência e punição no Brasil (2000-2016). Em C. B. Martins y S. Miceli (Orgs.). Sociologia brasileira hoje, pp. 143-216. São Paulo: Ateliê.

»Cecchetto, F. R., Muniz, J. e Monteiro, R. A. (2018). "Basta tá do Lado" - a construção social do envolvido com o crime. Caderno CRH, 31(82), 99-116. doi: https://doi.org/10.159o/ s0103-49792018000100007

" Cecchetto, F. R., Muniz, J. e Monteiro, R. A. (2020). Envolvido (a)-com o crime: tramas e manobras de controle, vigilância e punição. Revista de Estudos Empíricos em Direito, 7(2), 108-140. doi https://doi.org/10.19092/reed.v7i2.454

" Cefaï, D. (1996). La construction des problèmes publics. Définitions de situations dans des arènes publiques. Réseaux, 14(75), 43-66.

》Douglas, M. (1998). Como as instituições pensam. São Paulo: EDUSP.

" Fassin, D. (2008). Beyond good and evil? Questioning the anthropological discomfort. Anthropological Theory, 8(4): 333-344.

"Favret-Saada, J. (2005). Ser afetado. Cadernos de Campo, 13, 155-161.

》Foucault, M. (1990). A microfísica do poder. 9 ed. Rio de Janeiro: Graal.

" Foucault, M. (2009). Seguridad, territorio y población: curso en el Collège de France (19771978). Buenos Aires: Fondo de Cultura Económica.

》 Fridman, L. C. (2008). Morte e vida favelada. Em L. A. M. Silva (Org.). Vida sob Cerco: violência e rotina nas favelas do Rio de Janeiro, pp. 77-98. Rio de Janeiro: Editora Nova Fronteira.

» Gluckman, M. (1987). Análise de uma situação social na Zululândia moderna. Em B. Feldman-Bianco (Org.). Antropologia da Sociedade Contemporânea, pp. 227-344. São Paulo: Global. 
" Kant de Lima, R., Misse, M. e Miranda, A. P. M. (2000). Violência, criminalidade, segurança pública e justiça criminal no Brasil: uma bibliografia. BIB, 50, 45-123.

» Kant de Lima, R., Miranda, A. P. M. (2012). Estado, direito e sociedade: a segurança e a ordem pública em uma perspectiva comparada Em S. Durão e M. Darck (orgs.). Polícia, Segurança e Ordem Pública Perspectivas Portuguesas e Brasileiras, pp. 73-10o. Lisboa: Imprensa de Ciências Sociais.

»Lévi-Strauss, C. (1976). O Pensamento Selvagem. São Paulo: Companhia Editora Nacional.

"Miranda, A. P. M. (2015). Burocracia e Fiscalidade - Uma Análise Das Práticas de Fiscalização e Cobrança de Impostos. Rio de Janeiro: Lúmen Juris.

" Miranda, A. P. M. (2019). Nem aplicada, nem implicada: os percalços de uma antropologia enredada nos assuntos controversos e envolvida nos problemas públicos. Seminário 25 anos do Núcleo Fluminense de Estudos e Pesquisa (NUFEP - UFF). Recuperado de https://www.youtube.com/watch?v=Jgfy4r4dolo\&ab_channel=InEAC

» Miranda, A. P. M., Muniz, J. e Corrêa, R. M. (2019). Mapas de percepção de riscos: análise multimétodo de territorialidades afetadas pelo domínio armado. Rio de Janeiro: Autografia.

》Miranda, A. P. M. e Muniz, J. (2018). Dominio armado: el poder territorial de las facciones, los comandos y las milicias en Río de Janeiro. Revista Voces en el Fénix, 68, 44-49.

»Miranda, A. P. M. e Muniz, J. (2020). Armed Dominions. Em P. Amar (Ed.). Rio as Method. Duhram: Duke University Press. (no prelo)

» Miranda, A. P. M. e Pita, M. V. (2020). Stateness as Agency. Em P. Amar (Ed.). Rio as Method. Duhram: Duke University Press. (no prelo)

" Mitchell, J. C. (1987). A Questão da Quantificação na Antropologia Social. Em B. Feldman-Bianco (Org.). Antropologia das sociedades contemporâneas (pp. 77-126) São Paulo: Global.

» Montero, Paula. (2012). Controvérsias religiosas e esfera pública: repensando as religiões como discurso. Religião \& Sociedade, 32(1), 167-183. doi https://doi.org/10.1590/ So100-85872012000100008

» Muniz, J. (2014). Jogando o jogo democrático da segurança pública: procedimentos, transparência e responsabilização policiais. Em A.C. B. Pinto et al (Ed.). Tensões contemporâneas da repressão criminal, pp. 147-157. Porto Alegre: Livraria do Advogado.

" Muniz, J., Caruso, H. e Freitas, F. (2018). Os estudos policiais nas Ciências Sociais: um balanço sobre a produção brasileira a partir dos anos 2000. BIB, 84(2), 148-187. doi 10.17666/bib8405/2018

" Muniz, J. e Patrício, L. (2018). Segurança pública ou Proteção? Na corda bamba da cidadania nos 30 anos da Constituição. Em T. Monteiro (org.). Estado, Democracia e Direito no Brasil. Trinta anos da Constituição Cidadã, pp. 555-579. Rio de Janeiro, Editora Gramma.

» Muniz, J. e Proença Jr, D. (2007). Muita politicagem, pouca política os problemas da polícia são. Estudos Avançados, 21(61): 159-17

» Muniz, J. e Almeida, R. (2018). Respondendo às balas: segurança pública sob intervenção das palavras entrevista com Jacqueline Muniz. Trabalhos em Linguística Aplicada, 57(2), 993-1014. doi https://dx.doi.org/10.1590/010318138652393387341

» Nadel, S. F. (1951). The Foundations of Social Anthropology. London: Cohen \& West. 
»Pita, M. V. e Miranda, A. P. M. (2015). Alcance y limitaciones de las consultorías en materia de seguridad pública y derechos humanos: ¿es posible resistir a las generalizaciones y a los productos estandarizados? - Relato de una experiência. Civitas, 15, 128-154.

»Radcliffe-Brown, A. R. (1970). Preface. Em M. Fortes y E. Evans Pritchard (Eds.). African Political Systems, pp. xi-xxiii. Oxford: Oxford Univesity Press.

» Simmel, G. (2011). O conflito como sociação. Revista Brasileira de Sociologia da Emoção, $10(30), 568-573$.

»Souza Lima, A. C. (2014). Tutela: formação de Estado e tradições de gestão no Brasil. Rio de Janeiro: E-papers.

»Van Velsen, J. (1987). A análise situacional e o método de estudo de caso detalhado. Em B. Feldman-Bianco (Org.). Antropologia da Sociedade Contemporânea, pp. 345-374. São Paulo: Global.

»Weber, M. (1982). Ensaios de sociologia. sta. ed. Rio de Janeiro: Zahar.

»Yaccoub, H. M. (2011). Criminalização, coerção e o mercado produtivo de "gatos" de energia elétrica. IX Reunião de Antropologia do MERCOSUL.

»Zaluar, A. (1999a). Um debate disperso: violência e crime no Brasil da redemocratização. São Paulo em Perspectiva, 13(3): 3-17.

»Zaluar, A. (1999b). Violência e crime. Em S. Miceli. (Org.). O que ler na ciência social brasileira (1970-1995), pp. 13-107. São Paulo: Sumaré/Anpocs. 
